\title{
Invasion legacy effects versus sediment deposition as drivers of riparian vegetation
}

\author{
Zarah Pattison 1 - Robin Whytock $\cdot$ Nigel Willby
}

Received: 27 June 2017/ Accepted: 7 November 2017/Published online: 10 November 2017

(C) The Author(s) 2017. This article is an open access publication

\begin{abstract}
Riparian zones are formed by interactions between fluvio-geomorphological processes, such as sediment deposition, and biota, such as vegetation. Establishment of invasive alien plant (IAP) species along rivers may influence vegetation dynamics, evidenced as higher seasonal or inter-annual fluctuations in native plant diversity when IAP cover is high. This could impact the overall functioning of riparian ecosystems. Conversely, fine sediment deposited in riparian zones after floods may replenish propagule banks, thus supporting recruitment of native species. The interactive effects of invasion and fine sediment deposition have hitherto, however, been ignored. Vegetation surveys across rivers varying in flow regime were carried out over 2 years to assess changes in community composition and diversity. Artificial turf mats were used to quantify over-winter sediment deposition. The viable propagule bank in soil and freshly deposited sediment was then quantified by germination trials. Structural Equation Models were used to assess causal pathways between environmental variables, IAPs and native vegetation. Greater
\end{abstract}

Electronic supplementary material The online version of this article (https://doi.org/10.1007/s10530-017-1619-6) contains supplementary material, which is available to authorized users.

Z. Pattison $(\varangle) \cdot R$. Whytock $\cdot$ N. Willby

Department of Natural Sciences, University of Stirling,

Stirling FK9 4LA, Scotland, UK

e-mail: zarah.pattison@stir.ac.uk variation in flow increased the cover of IAPs along riverbanks. An increased in high flow events and sediment deposition were positively associated with the diversity of propagules deposited. However, greater diversity of propagules did not result in a more diverse plant community at invaded sites, as greater cover of IAPs in summer reduced native plant diversity. Seasonal turnover in the above-ground vegetation was also accentuated at previously invaded sites, suggesting that a legacy of increased competition in previous years, not recent sediment deposition, drives above-ground vegetation structure at invaded sites. The interaction between fluvial disturbance via sediment deposition and invasion pressure is of growing importance in the management of riparian habitats. Our results suggest that invasion can uncouple the processes that contribute to resilience in dynamic habitats making already invaded habitats vulnerable to further invasions.

Keywords Diversity Flow regime - Impatiens glandulifera $\cdot$ Sediment deposition $\cdot$ Structural equation modelling

\section{Introduction}

Riparian zones are complex and dynamic habitats noted for their high biodiversity (Naiman and 
Decamps 1997), yet are threatened by land use and channel management practices, altered hydrology (e.g., abstraction and flow regulation), climate change, and biological invasions (Flanagan et al. 2015). Their biodiversity is intimately linked to high spatial and temporal heterogeneity driven by fluvio-geomorphological processes and the potential for waterborne dispersal (hydrochory). However, invasive alien plants (IAPs) benefit from these same properties and commonly use riparian zones as corridors for dispersal (Naiman and Decamps 1997). Meteorological and river level data for the UK point to a recent and ongoing increase in runoff, resulting in a greater frequency of high-flow events in autumn and winter, especially in the north and west (Hannaford 2015). Combined with disturbance by sediment deposition this may facilitate colonisation and establishment of IAPs, thus potentially impacting native vegetation and the overall functioning of riparian ecosystems (Richardson et al. 2007).

Many factors including climate, flow and sediment deposition interact to mediate plant invasions and their effects along river corridors (Capon and Brock 2006; Truscott et al. 2006). Despite this, the interactions between these biotic and abiotic factors across time and space are rarely investigated when seeking to explain the distribution of native and non-native plant species (McShane et al. 2015). One of the most important physical functions of riparian areas is to trap and buffer the transfer of sediment (Steiger and Gurnell 2003). Riparian vegetation modifies sediment transport either by altering channel hydraulics or by physically entrapping materials, most significantly in lowland environments (Moggridge et al. 2009). There is growing interest in sedimentation processes in rivers and the link to flood events (Steiger and Gurnell 2003), partly driven by climate-related changes in flow regime and increased awareness of the link between land management and fine sediment entry to rivers. Large amounts of deposited sediment may bury or otherwise disturb pre-existing vegetation and the legacy seedbank, (Nilsson et al. 1993) but can favour early successional stages by creating invadible patches (Nilsson and Svedmark 2002). Seedling density commonly declines with increasing sediment depth (Dittmar and Neely 1999), and sediment deposition may thus uncouple the seedbank from developing or existing vegetation. However, evidence from Goodson et al. (2003) indicates that large numbers of propagules can also be deposited in association with this sediment. Seed banks are a key reserve of viable propagules that play a central role in recruitment, facilitating the storage and establishment of both native and non-native species (Gioria and Pyšek 2015). Thus it is critical to understand how they contribute to the resilience of riparian vegetation in the face of invasion and increased sediment loading.

Riparian habitats are integral to good river ecosystem function and riverbanks are the epicentre of hydraulic, geomorphological and ecological changes within the riparian zone (Goodson et al. 2003). Longterm (decadal) deposition rates are important in the geomorphological development of riparian zones. However, assessing annual (short-term) rates is important for understanding the more dynamic relationships between sedimentation and the biodiversity of riparian zones (Steiger and Gurnell 2003). The cumulative contribution of short- and long-term deposition rates may produce a legacy effect with immediate short-term implications for riparian vegetation and eventual long-term impacts on both vegetation and propagule banks (Corenblit et al. 2007). Although riparian zones are inherently dynamic, the imposition of multiple stressors, such as invasion by IAPs and increased sediment deposition, associated with land-use change and climate-related changes in flow, may lower community stability or affect long term resilience.

In this study we focus principally on the IAP Impatiens glandulifera Royle which is widespread along British and European rivers and has been associated with negative impacts on native riparian vegetation (Hejda et al. 2009; Pyšek et al. 2012), although two other major IAPs, Heracleum mantegazzianum Sommier \& Levier and Fallopia japonica (Houtt.) Ronse Decr. 1988, were commonly also present at our sites. The aim of this study was to (1) assess the contribution of IAPs and over-winter sediment deposition to short-term (inter-annual) changes in native vegetation composition and diversity and (2) disentangle the direct and indirect relationships regulating or impacting the abundance of IAPs and propagules. We hypothesized that high cover of IAPs would increase turnover and reduce plant diversity, thus destabilising native vegetation, but that greater sediment deposition over-winter may increase diversity by creating canopy gaps and acting as a propagule reservoir. This may mitigate negative 
impacts of IAP cover on native diversity and composition, with changes in the propagule bank associated with over-winter deposition being the primary driver of change in vegetation composition. Alternatively, in invaded catchments some IAPs may benefit disproportionately from changing flow regimes and increased sediment loading to the riparian zone.

\section{Methods}

Field surveys

Surveys were conducted across 20 lowland rivers in Central Scotland, UK (Appendix 1). Rivers ranged between 10 and $75 \mathrm{~m}$ in channel width and 5-40 $\mathrm{m}$ in elevation above sea-level. They also showed a gradient in mean annual flow increase over the last 22 years, ranging from 4 to $28 \%$ (Appendix 2). Initial site searches that confirmed the widespread extent of $I$. glandulifera relative to the other IAPs, therefore, sites were selected that contained at least this species and were concentrated at the most downstream accessible point on each river. This species is the most frequently occurring IAP across rivers in Scotland and regularly forms continuous monocultures along lowland rivers (Seager et al. 2012; Pattison et al. 2017). Sites varied in their level of invasion (quantified by \% cover of IAPs), thus affording a gradient of potential invasion impact. Vegetation surveys were conducted during August 2013 (year 1 summer), May 2014 (year 2 spring) and August 2014 (year 2 summer), in order to quantify turnover between seasons and years. Surveys began at a randomly selected point along a $100 \mathrm{~m}$ reach. At the start of each surveyed reach, a transect was established perpendicular to the water's edge and three plots, each of $1 \mathrm{~m}^{2}$, were positioned equidistantly between the water's edge (Q1), mid-bank height (Q2) and the bank top (Q3). A new transect was established every $10 \mathrm{~m}$, with seven transects per site. A total of 21 plots were thus sampled within each site, with a combined total of 420 plots sampled across all rivers in each field season. All species were identified and cover was quantified using a five point score adopted by the Joint Nature Conservation Committee (JNCC) for river macrophyte surveys. Scores were then converted to percentages based on the mid-point of the associated cover range.
Alien species were defined according to Preston et al. (2002) as those which colonised Britain with the aid of humans. In addition to I. glandulifera, $H$. mantegazzianum and $F$. japonica other IAPs recorded included Claytonia sibirica L., F. sachalinensis (F.Schmidt) Ronse Decr. 1988, F. x bohemica (Chrtek \& Chrtková) J.P. Bailey and Mimulus guttatus (DC.) G.L.Nesom and, within the propagule bank, Epilobium brunnescens (Cockayne) P. H. Raven \& Engelhorn. Percentage cover of all invasive alien species were combined and used to assess the effect of IAP cover on aspects of the native community. Impatiens glandulifera accounted for $90 \%$ of the total cover of recorded IAPs. Species most frequently recorded across all seasons during vegetation surveys were $I$. glandulifera, Urtica dioica L., Phalaris arundinacea L., Aegopodium podagraria L., Galium aparine L. and Arrhenatherum elatius (L.) P.Beauv. ex J.Presl \& C.Presl, 1819. Ficaria verna Huds. 1762 was also abundant in spring year 2, whilst Calystegia sepium (L.) R.Br. and the grasses Elymus repens (L.) Gould, Holcus lanatus L. and Brachypodium sylvaticum (Huds.) Beauv. were frequent in summer of both years.

Propagule bank collection

Overwinter deposition of propagules was measured using artificial turf (Astroturf) mats (Gurnell et al. 2007a). Each mat was $30 \times 30 \mathrm{~cm}$, with $1.5 \mathrm{~cm}$ length bristles. Eighteen mats were distributed evenly at each site (and up to $200 \mathrm{~m}$ upstream) across the three bank zones in late September 2013 (year 1) to ensure coverage of the range of conditions (i.e., variation in bank slope) for deposition of material. Mats were retrieved in March 2014 (year 2) and stored in sealed plastic bags for up to 2 weeks at $4-8{ }^{\circ} \mathrm{C}$ until processed. All mats were weighed to determine spatial (between site and across the river bank) patterns of overwinter deposition of sediment. This method provides a direct measure of sedimentation at discrete sites, over specific time periods and is indicative of the potential for hydrochory to contribute propagules to the riparian propagule bank (Steiger and Gurnell 2003).

\section{Germination trial}

The seedling emergence method was used to quantify the propagule bank, in which the abundance of 
individual species is estimated by identification of seedlings, following greenhouse germination of soil samples (Gurnell et al. 2007b). Astroturf mats were punctured to allow moisture exchange after watering and were then placed in trays previously filled with 3-4 cm sterile soil (John Innes \#2) (Gurnell et al. 2007b). Mats with little deposited sediment were augmented with additional sterile soil to prevent desiccation and to provide adequate rooting depth for seedlings $(2-3 \mathrm{~cm})$. Samples were then arranged randomly in polytunnels. Polytunnels were left unheated to ensure exposure of seeds to a wide range of temperatures, broadly resembling those encountered in the field, and were watered twice daily (10 min per watering) using an automated pipe-feed system. Such conditions have been found to be highly conducive to germination of a wide range of species (Abernethy and Willby 1999). As seeds germinated, they were identified to species level and then removed or, where further growth was needed for identification purposes, grown on in separate pots to prevent overcrowding. Once plants had flowered and could be identified they were removed to prevent reseeding. Wherever possible seedlings were identified to species level, although in a small number of cases $(<5 \%$ of individuals) it was only possible to identify to genus. The number of seedlings germinating was counted weekly to ensure that seedlings did not emerge and die between counts. Although the seedling emergence method may underestimate absolute seed density it is a good comparative measure of the viable portion of the seed bank (Abernethy and Willby 1999). The germination trial began in April 2014 and was terminated in September 2014 (Year 2) following a month with negligible emergence of seedlings of species not already recorded. Species found most frequently during the germination trial were the grasses Poa annиa L., Agrostis stolonifera L., 1753, H. lanatus and $P$. arundinacea plus the rushes Juncus effusus L. and $J$. bufonius L.. The commonest herbaceous perennials were Epilobium hirsutum L., Rumex obtusifolius L. and $U$. dioica.

\section{Hydrological indices}

Daily mean flow data were obtained from the Centre of Ecology and Hydrology's National River Flow Archive. Data from 1990 to 2014 were used to derive various hydrological indices, using data from the most downstream flow gauging station on each surveyed river. Flood frequency, expressed as the mean number of days per year on which flows exceeded a threshold of five times the median flow (FFE*5), was used as an indicator of fluvial disturbance. The coefficient of variation $(\mathrm{CoV})$ in daily mean flows was also calculated and used to express the variability in flow for each river. These indices capture contrasting but ecologically-relevant components of flow regime (Clausen and Biggs 1997), with flood frequency and flow variability having been shown to affect riparian vegetation (Riis et al. 2008) and physical processes, such as sediment transport and deposition (Nilsson and Svedmark 2002).

\section{Diversity indices}

To quantify temporal turnover of native species in above-ground vegetation Bray-Curtis dissimilarity (BCI) was calculated using species cover data (\%, square-root transformed) for three contrasts: Summer year 1 versus spring year 2; summer year 1 versus summer year 2; and spring versus summer in year 2 . Native species diversity was calculated using Shannon's diversity index on above-ground vegetation (based on \% cover) for year 2 spring and summer, as well as for the propagule bank vegetation on the mats (based on numbers of seedlings).

\section{Structural equation modelling}

Piecewise structural equation models (confirmatory path analysis; Shipley 2009; Lefcheck 2016) were used to test relationships between environmental measures (river flow regime, amount of sediment deposited, river bank elevation), the number and diversity of propagules deposited over winter, seasonal cover of IAPs and five response variables of interest (native plant diversity and different components of turnover of above-ground native vegetation). This multivariate technique is useful for testing a priori defined models and quantifying the relative importance of explanatory variables. SEM can also test whether a given effect is direct (e.g., IAP cover influences native plant diversity) or indirect (e.g., flow regime influences IAP cover, which influences native plant diversity) (Shipley 2009; Lefcheck 2016). We developed a conceptual model (meta-model) detailing potential cause-effect relationships based on 
biological relevance in the literature or logical arguments to guide the modelling process (Fig. 1). We expected that greater cover of IAPs increases turnover and reduces above-ground plant diversity, particularly at already invaded sites, thus destabilising native vegetation, but that greater deposition of sediment over winter will counter the impact of IAPs on native diversity by creating canopy gaps and acting as a propagule reservoir. Other factors which may indirectly impact IAP cover include the frequency and variability of flood events, which could both reduce IAP cover and increase sediment inputs. Thus, overwinter sediment deposition will be the primary driver of change in above-ground native vegetation.

Prior to SEM analyses, all explanatory variables were examined for normality and transformed when necessary. To construct the structural equation models (SEMs) linear mixed effects models (LMMs) with a Gaussian error structure were used. River was

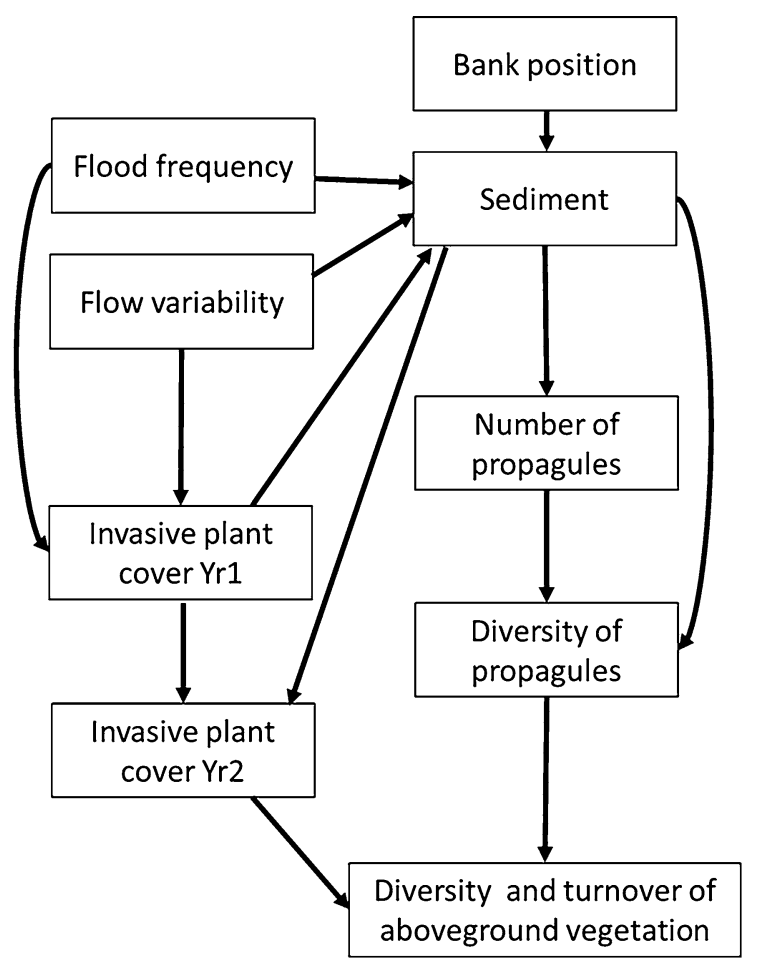

Fig. 1 Conceptual meta-model representing hypothesized causal relationships between variables. Environmental (flow variability and frequency, sediment deposition and bank elevation) and biological (propagule diversity and abundance, invasive plant cover) variables are hypothesized to have direct and indirect effects on diversity and turnover of above-ground vegetation included as a random intercept to account for pseudoreplication. All predictors were standardised to one standard deviation prior to statistical analyses in order to compare effect sizes of each predictor. We checked for multicollinearity among predictor variables within constituent LMMs, none of which were highly correlated $(r \leq 0.60)$.

During model validation, missing paths were evaluated. This evaluation process suggests possible relevant relationships between variables that were not specified in the initial model. These pathways were then either added to the model if they were considered to be causal, or otherwise allowed to freely covary. Upon model validation a significant missing path was identified, the effect of mean annual flood frequency on the diversity of propagules, and added to the SEM. Fisher's C [Shipley's test of directed separation; (Shipley 2009)] was used to evaluate SEM fit, where higher $P$ values $(>0.05)$ indicate that the data supports the model (i.e., $\mathrm{H}_{0}=$ no difference between the data and the hypothesised paths). However, it should be noted that alternative models could also support the data, and for one response variable (BCI spring $\mathrm{v}$ summer Yr2), two alternative SEMs were constructed based on a priori hypotheses, and the best model in this case was selected using AICc. $\mathrm{R}^{2}$ values (Nakagawa and Schielzeth 2013) are reported for each constituent LMM within a SEM. All statistical analyses were conducted using R 3.2.2 (R Core Team 2017), with the additional $\mathrm{R}$ packages vegan (Oksanen et al. 2017), nlme (Pinheiro et al. 2017) and piecewiseSEM (Lefcheck 2016).

\section{Results}

Above-ground plant diversity

The SEM for summer plant diversity was well supported by the data (Fisher's C $=40.14$, $P=0.38)$. Contrary to expectation, greater variation in flow increased IAP cover in year 1 (Beta $=0.40$, $\mathrm{SE}=0.15, P=0.02$ ), which led to higher IAP cover in summer year 2 (Beta $=0.44, \quad \mathrm{SE}=0.12$, $P \leq 0.01)$. This subsequently led to a decline in the diversity of native vegetation (Beta $=-0.26$, $\mathrm{SE}=0.13, P=0.05$ ), and thus flow regime indirectly reduced diversity of native vegetation in summer through its direct effects on IAP cover. The 
diversity of viable propagules deposited over winter (between years 1-2) was positively associated with both the weight of sediment deposited (Beta $=0.32$, $\mathrm{SE}=0.11, P \leq 0.01)$ and the mean annual flood frequency $\quad\left(\mathrm{FFE}^{*} 5\right) \quad($ Beta $=0.28, \quad \mathrm{SE}=0.13$, $P=0.04)$. However, in contrast to expectations, this did not affect the diversity of native vegetation. Although we found a weak positive relationship between IAP cover in year 1 and the amount of sediment deposited $\quad($ Beta $=0.21, \quad \mathrm{SE}=0.12$, $P=0.09$ ), this deposition did not directly or indirectly influence summer native plant diversity in year 2, also contradicting expectations (Fig. 2).

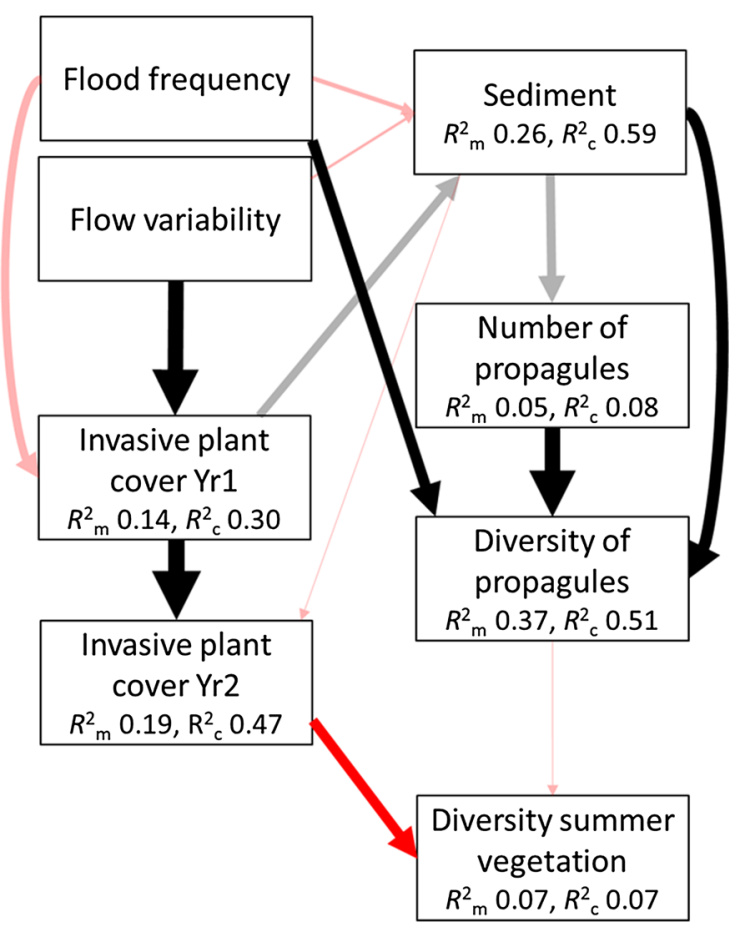

Fig. 2 Structural equation model (SEM) exploring the effects of over-winter sediment deposition and invasive alien plant cover on diversity of above-ground native plant communities in summer (year 2). Boxes represent measured variables. Arrows represent unidirectional relationships among variables. Black arrows denote positive relationships, and red arrows negatives ones. Arrows for non-significant paths $(P>0.05)$ are semitransparent. The thickness of the significant paths is scaled relative to the magnitude of the standardized regression coefficient. Both the marginal $\mathrm{R}^{2}\left(\mathrm{R}_{\mathrm{m}}^{2}\right)$ explaining the fixed effect component and the conditional $\mathrm{R}^{2}\left(\mathrm{R}_{\mathrm{c}}^{2}\right)$ explaining both the fixed and random effects are shown for each response variable
For above ground plant diversity in spring we found no direct or indirect relationships between and predictor variables. Results are given in Appendix 3.

Turnover of vegetation

Of the two competing models predicting vegetation turnover between spring and summer year 2, invasive cover (year 1 summer) as a predictor of turnover between spring and summer in year 2 had the greatest support (dAICc 136.22). The competing model showed no direct pathway between invasive cover in spring or summer (year 2), and had lower support based on AICc $(\mathrm{dAICc}=127.89$; Appendix 3$)$. Goodness of fit statistics for each of the SEMs are given in Appendix 3. Greater invasive cover in year 1 was associated with increased dissimilarity between the above-ground vegetation in spring and summer of year 2 (Beta $=0.30, \mathrm{SE}=0.12, P=0.02$; Fig. 3 ). We expected a greater diversity of propagules to increase or maintain the similarity of established vegetation, either between seasons or inter-annually (therefore aiding native community stability), but this effect was weak (Beta $=-0.20, \quad \mathrm{SE}=0.12$, $P=0.10)$. All other direct and indirect pathways showed the same pattern as the SEMs for aboveground plant diversity (Appendix 4).

For the primary response variables of turnover between summer year 1 and 2 and turnover between summer year 1 and spring year 2, we found no significant relationships between variables (Appendix 4).

\section{Discussion}

Over-winter sediment deposition following floods is widely regarded as an important mechanism for plant dispersal and colonisation in riparian habitats (Andersson and Nilsson 2002; Gurnell et al. 2008). Large quantities of plant propagules have been recorded in freshly deposited sediment which, by creating gaps, may provide recruitment opportunities in aboveground vegetation, yet the potential link between IAPs and sediment deposition has received limited attention (Baattrup-Pedersen et al. 2013). This is surprising given the growing interest and awareness of the ecological impacts of fine sediment in rivers (Jones et al. 2012) and the linkages to channel management 


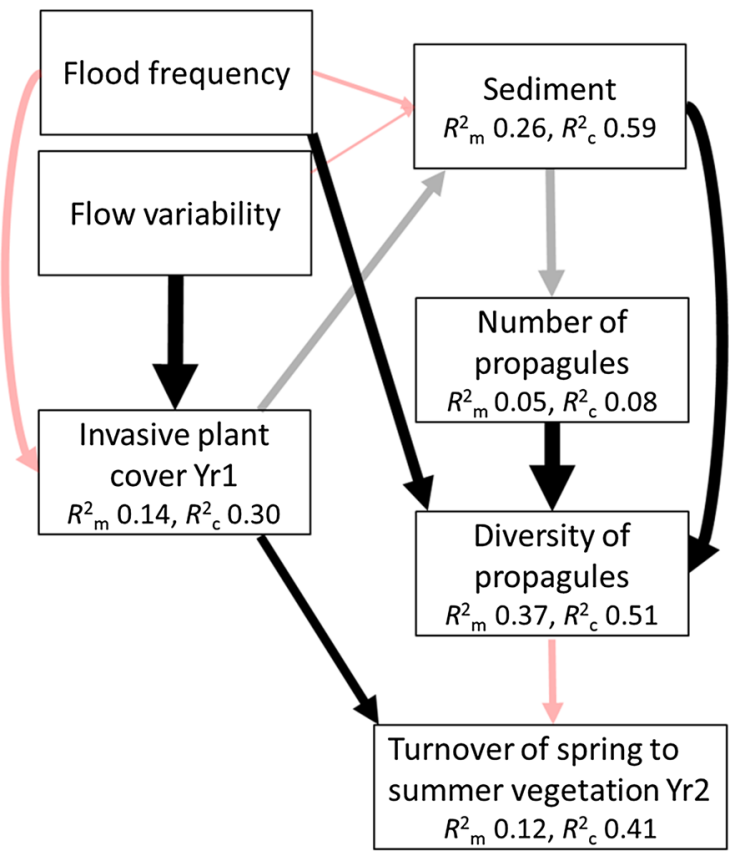

Fig. 3 Structural equation model (SEM) exploring the effects of over-winter sediment deposition and invasive alien plant cover on turnover of above-ground native plant communities between spring and summer (year 2). Boxes represent measured variables. Arrows represent unidirectional relationships among variables. Black arrows denote positive relationships, and red arrows negatives ones. Arrows for non-significant paths $(P>0.05)$ are semi-transparent. The thickness of the significant paths is scaled relative to the magnitude of the standardized regression coefficient. Both the marginal $R^{2}\left(R_{m}^{2}\right)$ explaining the fixed effect component and the conditional $R^{2}\left(R_{c}^{2}\right)$ explaining both the fixed and random effects are shown for each response variable

and land use practices and climate-induced change in river flows. Our study showed that short term changes in flow regime positively impact invasion cover which reduces above-ground native plant diversity in summer. Both an increase in annual flood events and sediment loading were positively associated with the diversity of propagules deposited at a site. However, above-ground diversity was dictated by the competitive effects of IAPs rather than by recruitment from the viable propagule bank formed through sediment deposition. Seasonal turnover in the above-ground vegetation was also accentuated at sites with a history of invasion. Heavily invaded sites were associated with lower native plant diversity in summer, suggesting that a legacy effect of competition in previous years, not disturbance via sediment deposition, was the more important determinant of established native vegetation structure at invaded sites.

Environmental impact of invasive alien plants and sediment deposition

Fluvial disturbance, expressed via changes in flow regime and sediment deposition, can potentially influence riparian vegetation structure on both a short temporal and fine spatial scale (Steiger et al. 2003) through the scouring or burial of existing vegetation which creates patches of varying size, quality and longevity. Competition between IAPs and native vegetation is often regulated by local environmental conditions (Pattison et al. 2017). Therefore, interannual changes in environmental conditions may either constrain the growth and thereafter the impact of IAPs locally, aid their establishment via enhanced propagule supply to newly created patches, or, once dense monocultures are established, have no further measurable effect (Bellard et al. 2013). Dominance by IAPs may subsequently lead to less resilient and diverse plant communities over the short term, if certain species are filtered out through competition or other changes in the environment that accompany invasion (Gaertner et al. 2014). This impact may, however, be reversed if sediment deposition during flood events lowers competitive ability of IAPs by reducing their cover and favours recruitment of native species, whether from the in situ propagule bank or recent deposition (Steiger et al. 2003).

River flows and autumn-winter flooding have increased since the 1960s, especially in the north and west of Britain (Hannaford 2015), thereby increasing the potential for fluvial disturbance. However, neither the variability in long term flow nor the increase in annual flood frequency could explain variation in the amount of sediment deposited. It may be that different aspects of flow regime, such as the duration of flood events, are more important in determining depositional processes. Goodson et al. (2002), for example, found that the duration of inundation was strongly related with riverbank sediment deposition along the River Dove, UK. The amount of sediment deposited also decreased away from the water's edge, consistent with higher bank elevations rarely being inundated with flood water for an extended duration (Goodson et al. 2002). Catchment topography, aspects of channel morphology, and land use may also override the likely 
influence of flow regime on sediment inputs (Jones et al. 2012). Contrary to our expectations, and other evidence (Catford et al. 2011), that a reduction in fluvial disturbance would favour expansion of invasive cover, we found that variability in flow was positively associated with IAP cover in summer. It may be that other species were impacted disproportionately and IAPs therefore benefited from reduced competition, resulting from fluvial disturbance, which has been associated with invasion in other habitat types (Hood and Naiman 2000). Most of the flow variability and flood events also occurred during winter on the rivers we studied. Alternatively therefore, annual IAPs such as I. glandulifera, which do not over-winter (Beerling and Perrins 2012), might be favoured by increased inputs of resources to the riparian zone when establishing in the following spring.

Propagule deposition and above ground plant diversity

In our study both the amount of sediment and incidence of flooding were, as expected, positively associated with diversity of the over-winter propagule bank. Sediment transport has the potential to increase the available propagule bank within riparian zones, since propagules are also transported at times of flood (Nilsson et al. 2010) and deposited along with sediment in low energy environments. Patches of freshly deposited sediment thus represent gaps characterised by high levels of nutrients, organic matter and high densities of viable propagules (Nilsson and Svedmark 2002).

Although deposited sediments contain a propagule reservoir of native species, these may be unable to germinate or establish (Goodson et al. 2003). Our study showed that the above-ground vegetation diversity at invaded sites in summer was, in fact, independent of the diversity of the available propagule bank. Floods or other disturbances frequently create gaps, which, in conjunction with propagule deposition, could provide an effective mechanism for increasing diversity in riparian zones (Jansson et al. 2005). However, it seems that diversity of above-ground vegetation at invaded sites is determined more by competition with IAPs (or other local abiotic factors that moderate this competition), rather than propagule supply. This suggests that IAPs have a greater influence on the above-ground vegetation than do abiotic factors, potentially through suppressing germination of native species (Gioria and Osborne 2009) or because the native propagule supply is intrinsically diminished in highly invaded sites. Sites with established invasions may be reflective of a degraded upstream catchment, with the quality of seed rain being reduced by anthropogenic pressures or through competition from a range of IAPs. Any potentially positive effect via sediment loading on diversity of propagules is evidently masked by IAPs, suggesting that uninvaded sites subject to the same pressures of sediment loading will respond differently to the increased opportunities for recruitment.

Seasonal turnover of vegetation and invasion legacy

Invasions are often associated with highly disturbed habitats (Diez et al. 2012). Initial colonisation typically exploits gaps created by disturbance (Richardson et al. 2007) before expanding to form large monospecific stands. In this study we asked whether high levels of invasion along riverbanks were associated with short term instability of vegetation, which might reinforce further invasion by a feedback process. Turnover in above-ground vegetation was greatest between summer year 1 and 2, however neither sediment, propagule deposition, flow regime or IAP cover contributed to these inter-annual changes.

Greater turnover in vegetation composition between spring and summer of year 2 was associated with a higher cover of IAPs in year 1. Some turnover in composition is to be expected simply due to seasonality but our results show that this seasonal turnover was accentuated by invasion. Riparian vegetation is influenced more strongly by competitive effects of invasion in summer when IAPs form monocultures which can outcompete native plant species for space and light (Vilà et al. 2011). In spring, however, riparian vegetation is controlled mainly by abiotic conditions (Pattison et al. unpublished), with differences in composition between sites being small in relation to level of invasion when compared to the differences observed in the summer. Invasion by IAPs hence represents an additional influence on vegetation composition and phenology. 


\section{Conclusion}

The plant propagule bank formed by over-winter deposition is a potential pool of recruits to the riparian vegetation but our results show that IAPs can uncouple this linkage. We conclude that above-ground vegetation at invaded sites is driven less by recruitment from propagules deposited over-winter and more by the legacy effect of competition with IAPs over previous years. This impacts both diversity and turnover within the above-ground vegetation at heavily invaded sites through gradual displacement of dominant native species. Observational studies under field conditions are important to understand community responses to invasion since these invariably occur against a backdrop of climate- and land use-related changes in flow regime and sediment loading. Such studies offer insights into the relative importance of different drivers in regulating competitive interactions between established native riparian and alien plant species (Flanagan et al. 2015), thereby flagging opportunities to influence these interactions through management.

Acknowledgements We gratefully acknowledge financial support from Scottish Natural Heritage and the Scottish Environment Protection Agency. The manuscript was improved after feedback from two anonymous reviewers. The authors declare they have no conflict of interest regarding this manuscript.

Open Access This article is distributed under the terms of the Creative Commons Attribution 4.0 International License (http:// creativecommons.org/licenses/by/4.0/), which permits unrestricted use, distribution, and reproduction in any medium, provided you give appropriate credit to the original author(s) and the source, provide a link to the Creative Commons license, and indicate if changes were made.

\section{References}

Abernethy VJ, Willby NJ (1999) Changes along a disturbance gradient in the density and composition of propagule banks in floodplain aquatic habitats. Plant Ecol 140:177-190

Andersson E, Nilsson C (2002) Temporal variation in the drift of plant litter and propagules in a small boreal river. Freshw Biol 47:1674-1684

Baattrup-Pedersen A, Dalkvist D, Dybkjær JB et al (2013) Species recruitment following flooding, sediment deposition and seed addition in restored riparian areas. Restor Ecol 21:399-408. https://doi.org/10.1111/j.1526-100X. 2012.00893.x
Beerling DJ, Perrins JM (2012) Impatiens glandulifera Royle (Impatiens roylei Walp.). J Ecol 81:367-382

Bellard C, Thuiller W, Leroy B et al (2013) Will climate change promote future invasions? Glob Change Biol 19:3740-3748. https://doi.org/10.1111/gcb.12344

Capon SJ, Brock MA (2006) Flooding, soil seed bank dynamics and vegetation resilience of a hydrologically variable desert floodplain. Freshw Biol 51:206-223. https://doi.org/ 10.1111/j.1365-2427.2005.01484.x

Catford JA, Downes BJ, Gippel CJ, Vesk PA (2011) Flow regulation reduces native plant cover and facilitates exotic invasion in riparian wetlands. J Appl Ecol 48:432-442

Clausen B, Biggs BJ (1997) Relationships between benthic biota and hydrological indices in New Zealand streams. Freshw Biol 38:327-342

Corenblit D, Tabacchi E, Steiger J, Gurnell AM (2007) Reciprocal interactions and adjustments between fluvial landforms and vegetation dynamics in river corridors: a review of complementary approaches. Earth-Sci Rev 84:56-86. https://doi.org/10.1016/j.earscirev.2007.05.004

Diez JM, D'Antonio CM, Dukes JS et al (2012) Will extreme climatic events facilitate biological invasions? Front Ecol Environ 10:249-257. https://doi.org/10.1890/110137

Dittmar LA, Neely RK (1999) Wetland seed bank response to sedimentation varying in loading rate and texture. Wetlands 19:341-351. https://doi.org/10.1007/BF03161765

Flanagan NE, Richardson CJ, Ho M (2015) Connecting differential responses of native and invasive riparian plants to climate change and environmental alteration. Ecol Appl 25:753-767. https://doi.org/10.1890/14-0767.1.sm

Gaertner M, Biggs R, Te Beest M et al (2014) Invasive plants as drivers of regime shifts: identifying high-priority invaders that alter feedback relationships. Divers Distrib 20:733-744. https://doi.org/10.1111/ddi.12182

Gioria M, Osborne B (2009) Assessing the impact of plant invasions on soil seed bank communities: use of univariate and multivariate statistical approaches. J Veg Sci 20:547-556. https://doi.org/10.1111/j.1654-1103.2009. 01054.x

Gioria M, Pyšek P (2015) The legacy of plant invasions: changes in the soil seed bank of invaded plant communities. Bioscience 66:40-53. https://doi.org/10.1093/biosci/biv165

Goodson JM, Gurnell AM, Angold PG, Morrissey IP (2002) Riparian seed banks along the lower River Dove, UK: their structure and ecological implications. Geomorphology 47:45-60. https://doi.org/10.1016/S0169-555X(02)00140-X

Goodson JM, Gurnell AM, Angold PG, Morrissey IP (2003) Evidence for hydrochory and the deposition of viable seeds within winter flow-deposited sediments: the River Dove, Derbyshire, UK. River Res Appl 19:317-334. https://doi. org/10.1002/rra.707

Gurnell AM, Goodson J, Thompson K et al (2007a) The riverbed: a dynamic store for plant propagules? Earth Surf Process Landf 1272:1257-1272. https://doi.org/10.1002/ esp. 1554

Gurnell A, Goodson JM, Thompson K et al (2007b) Three seedling emergence methods in soil seed bank studies: implications for interpretation of propagule deposition in riparian zones. Seed Sci Res 17:183. https://doi.org/10. 1017/S0960258507774718 
Gurnell AM, Thompson K, Goodson JM, Moggridge H (2008) Propagule deposition along river margins: linking hydrology and ecology. J Ecol 96:553-565. https://doi.org/10. 1111/j.1365-2745.2008.01358.x

Hannaford JA (2015) Climate-driven changes in UK river flows: a review of the evidence. Prog Phys Geog 39:29-48

Hejda M, Pyšek P, Jarošík V (2009) Impact of invasive plants on the species richness, diversity and composition of invaded communities. J Ecol 97:393-403

Hood WG, Naiman RJ (2000) Vulnerability of riparian zones to invasion by exotic vascular plants. Plant Ecol 148:105-114

Jansson R, Zinko U, Merritt DM, Nilsson C (2005) Hydrochory increases riparian plant species richness: a comparison between a free-flowing and a regulated river. $\mathrm{J}$ Ecol 93:1094-1103. https://doi.org/10.1111/j.1365-2745.2005. 01057.x

Jones JI, Collins AL, Naden PS, Sear DA (2012) The relationship between fine sediment and macrophytes in rivers. River Res Appl 28:1085-1095. https://doi.org/10.1002/rra

Lefcheck JS (2016) piecewiseSEM: piecewise structural equation modelling in $\mathrm{r}$ for ecology, evolution, and systematics. Methods Ecol Evol 7:573-579. https://doi.org/10.1111/ 2041-210X.12512

McShane RR, Auerbach DA, Friedman JM et al (2015) Distribution of invasive and native riparian woody plants across the western USA in relation to climate, river flow, floodplain geometry and patterns of introduction. Ecography (Cop) 38:1-12. https://doi.org/10.1111/ecog.01285

Moggridge HL, Gurnell AM, Mountford JO (2009) Propagule input, transport and deposition in riparian environments: the importance of connectivity for diversity. J Veg Sci 20:465-474. https://doi.org/10.1111/j.1654-1103.2009. 05498.x

Naiman RJ, Decamps H (1997) The ecology of interfaces: riparian zones. Annu Rev Ecol Syst 28:621-658. https:// doi.org/10.1146/annurev.ecolsys.28.1.621

Nakagawa S, Schielzeth H (2013) A general and simple method for obtaining R2 from generalized linear mixed-effects models. Methods Ecol Evol 4:133-142. https://doi.org/10. 1111/j.2041-210x.2012.00261.x

Nilsson C, Svedmark M (2002) Basic principles and ecological consequences of changing water regimes: riparian plant communities. Environ Manage 30:468-480. https://doi. org/10.1007/s00267-002-2735-2

Nilsson C, Nilsson E, Johansson ME et al (1993) Processes structuring riparian vegetation. Curr Top Bot Res $1: 419-431$

Nilsson C, Brown RL, Jansson R, Merritt DM (2010) The role of hydrochory in structuring riparian and wetland vegetation. Biol Rev Camb Philos Soc 85:837-858. https://doi.org/10. 1111/j.1469-185X.2010.00129.x

Oksanen J, Guillaume Blanchet G, Friendly M et al (2017) Vegan: community ecology package. $\mathrm{R}$ package version 2.4-3. https://CRAN.R-project.org/package=vegan
Pattison Z, Minderman J, Boon PJ, Willby N (2017) Twenty years of change in riverside vegetation: what role have invasive alien plants played? Appl Veg Sci. https://doi.org/ 10.1111/avsc. 12297

Pinheiro J, Bates D, DebRoy S, Sarkar D, R Core Team (2017) nlme: linear and nonlinear mixed effects models. R package version 3.1-131. https://CRAN.R-project.org/ package $=$ nlme

Preston CD, Pearman DA, Dines TD (2002) New atlas of the british and irish flora: an atlas of the vascular plants of britain, ireland, the isle of man and the channel islands. Oxford University Press, Oxford

Pyšek P, Jarošík V, Hulme PE et al (2012) A global assessment of invasive plant impacts on resident species, communities and ecosystems: the interaction of impact measures, invading species' traits and environment. Glob Chang Biol 18:1725-1737. https://doi.org/10.1111/j.1365-2486.2011. 02636.x

R Core Team (2017). R: a language and environment for statistical computing. R Foundation for Statistical Computing, Vienna. https://www.R-project.org/

Richardson DM, Holmes PM, Esler KJ et al (2007) Riparian vegetation: degradation, alien plant invasions, and restoration prospects. Divers Distrib. https://doi.org/10. 1111/j.1472-4642.2006.00314.x

Riis T, Suren AM, Clausen B, Sand-Jensen K (2008) Vegetation and flow regime in lowland streams. Freshw Biol 53:1531-1543. https://doi.org/10.1111/j.1365-2427.2008. 01987.x

Seager K, Baker L, Parsons Het al (2012) The rivers and streams of england and wales: an overview of their physical character in 2007-2008 and changes since 1995-1996. In: Boon PJ, Raven PJ (eds) river conservation and management. Wiley, Chichester, pp 27-41

Shipley B (2009) Confirmatory path analysis in a generalized multilevel context. Ecology 90:363-368. https://doi.org/ 10.1890/08-1034.1

Steiger J, Gurnell AM (2003) Spatial hydrogeomorphological influences on sediment and nutrient deposition riparian zones: observations from the Garonne River, France. Geomorphology 49:1-23. https://doi.org/10.1016/S0169555X(02)00144-7

Steiger J, Gurnell AM, Goodson JM (2003) Quantifying and characterizing contemporary riparian sedimentation. River Res Appl 19:335-352. https://doi.org/10.1002/rra.708

Truscott AM, Soulsby C, Palmer SCF et al (2006) The dispersal characteristics of the invasive plant Mimulus guttatus and the ecological significance of increased occurrence of highflow events. J Ecol 94:1080-1091. https://doi.org/10.1111/ j.1365-2745.2006.01171.x

Vilà M, Espinar JL, Hejda M et al (2011) Ecological impacts of invasive alien plants: a meta-analysis of their effects on species, communities and ecosystems. Ecol Lett 14:702-708. https://doi.org/10.1111/j.1461-0248.2011.01628.x 